Note

\title{
Novel insights into the early stages of infection by oval conidia of Colletotrichum
}

\section{sublineolum}

Ednéia Aparecida de Souza-Paccola ${ }^{1}$, Cleide Aparecida Bomfeti², Francisco André Ossamu Tanaka ${ }^{3}$, Nelson Sidnei Massola Junior $^{3}$, Nelson Barros Colauto ${ }^{4}$, José Edson Fontes Figueiredo ${ }^{5}$, Luzia Doretto Paccola-Meirelles ${ }^{1 *}$

\author{
${ }^{1}$ State University of Londrina - Dept. of Agronomy, C.P. 6001 \\ - 86051-980 - Londrina, PR - Brazil. \\ ${ }^{2}$ State University of Londrina - Dept. of General Biology. \\ 3University of São Paulo/ESALQ - Dept. of Plant Pathology \\ and Nematology, C.P. 09 - 13418-900 - Piracicaba, SP - \\ Brazil. \\ 4Paranaense University - Lab. of Molecular Biology, C.P. 224 \\ - 87502-210 - Umuarama, PR - Brazil. \\ ${ }^{5}$ Embrapa Maize \& Sorghum - Molecular Biochemistry Lab. - \\ C.P. 151 - 35701-970 - Sete Lagoas, MG - Brazil. \\ *Corresponding author <paccola@uel.br> \\ Edited by: Emerson Medeiros Del Ponte
}

Received December 02, 2014

Accepted February 20, 2015
ABSTRACT: Anthracnose, caused by Colletotrichum sublineolum Henn. ex Sacc. \& Trotter, is one of the most important sorghum [Sorghum bicolor (L.) Moench] diseases in Brazil. This fungus exhibits conidial dimorphism, producing either falcate or oval conidia on solid and liquid media, respectively. We compared patterns of the initial infection events by these two types of conidia on sorghum leaves using light microscopy and scanning electron microscopy. The infection events during the first $24 \mathrm{~h}$ were similar for both oval and falcate conidia. Globose and melanized apressoria were formed at $24 \mathrm{~h}$ after inoculation (hai) regardless of the conidia type. Dense mycelium and oval conidia developed from germinated falcate conidia at 32 hai. Hyphal mass displaying acervuli filled with falcate conidia and surrounded by setae, developed from germinated oval conidia at 48 hai. Oval conidia were as capable as falcate conidia of infecting sorghum leaves. The inherent ability to grow faster and the easeness with which oval conidia can be produced in vitro as compared to falcate, make the former a preferred choice for studies on the $C$. sublineolum-sorghum interaction. It would be instructive to further investigate the potential role of the oval conidia in epidemics.

Keywords: Sorghum bicolor, anthracnose, conidial dimorphism, infection biology, secondary sporulation

\section{Introduction}

Anthracnose, caused by Colletotrichum sublineolum Henn. ex Sacc. \& Trotter, is one of the most important diseases affecting sorghum [Sorghum bicolor (L.) Moench] crops (Wang et al., 2006; Perumal et al., 2009). Symptoms can occur in any aerial part of the plant, and result in yield losses in excess of $50 \%$, depending on cultivar, inoculum source, and environmental conditions favorable for epidemics (Powell et al., 1977; Casela et al., 2001). Disease symptoms are characterized by the formation of elliptic and circular lesions, up to $5 \mathrm{~mm}$ in diameter, with reddish, orangish, dark purple or brown edges, depending on the cultivar. Numerous dark-colored acervuli are formed in the center of the lesions and a great quantity of conidiophores is produced inside the acervuli. Erect, hyaline, aseptate, and falciform shaped conidia produced terminally on conidiophores are referred to as falcate conidia (Sutton, 1980; Warren, 1986).

A second type of conidia, the oval conidia, was found in C. sublineolum (Souza-Paccola et al., 2003). They are smaller than falcate conidia, oval to elliptic in shape and, although the falcate conidia are more common in this species, the oval conidia are easier to produce in vitro than the falcate conidia. The latter are produced in solid culture and are light-dependent, whereas the oval conidia are produce in liquid culture only and they are light-independent.

Both conidia types were observed during an infection of maize (Zea mays L.) leaves by C. graminicola (Nishi- hara, 1975; Panaccione et al., 1989). For this species, falcate conidia are produced blastically from hyphae that do not have differentiated conidiogenous cells while oval conidia are produced directly from hyphae (Panaccione et al., 1989). Souza-Paccola et al. (2003) showed the possibility of using oval conidia of $C$. sublineolum for genetic and pathogenic studies, especially for isolates that fail to produce falcate conidia. Typical anthracnose symptoms were observed when oval conidia were injected into the leaf nervures and stems of sorghum in the greenhouse. Nishihara (1975) reported that inoculation of maize leaves using suspensions of oval conidia of $C$. graminicola isolates resulted in higher disease intensity compared to suspensions of the falcate conidia. Conversely, such a difference was not found in another study which compared these two types of conidia (Panaccione et al., 1989).

Although the infection capacity for the oval conidia has been demonstrated (Souza- Paccola et al., 2003), detailed information is lacking about the formation, germination and penetration events of the oval conidia of C. sublineolum in sorghum plants as compared to falcate conidia. Therefore, this study aimed to provide novel insights into the early stages of infection of sorghum leaves by the oval conidia of $C$. sublineolum.

\section{Materials and Methods}

\section{Falcate and oval conidia production}

Two strains of C. sublineolum, BR 204.01 and BR 85.02 were used in this study. These strains were grown 
on agar oatmeal culture medium, under continuous fluorescent light $\left(50 \mu \mathrm{E} \mathrm{m}^{-2} \mathrm{~s}^{-1}\right)$ for seven days at $22 \pm 3{ }^{\circ} \mathrm{C}$, prior to the production of both types of conidia. Falcate conidia production was induced after scraping mycelia with a sterilized metal blade and incubating under the same conditions for seven to ten days. Oval conidia were produced in liquid culture (Souza-Paccola et al., 2003). Three mycelial discs (each $10-\mathrm{mm}$ in diameter) of each strain were transferred to flasks containing $50 \mathrm{~mL}$ of potato broth medium culture, which were shaken for four days under the same incubation conditions. Mycelia were filtered through a sterile cheesecloth and oval conidia were recovered from the filtered liquid after centrifugation at $6,000 \mathrm{~g}$ for $5 \mathrm{~min}$. The pellet containing oval conidia was resuspended in $2 \mathrm{~mL}$ of a sterile aqueous solution with $0.01 \%$ Tween 80 .

\section{Plant production and maintenance}

Plants from a susceptible sorghum cultivar, BR009 (Casela et al., 2001), were grown in plastic pots (each15$\mathrm{cm}$ in diameter) containing a mixture of peat, perlite and soil $(1: 2: 1)$ in a greenhouse for $20-25$ days in a $12 / 12 \mathrm{~h}$ light/dark cycle.

\section{Oval conidia morphogenesis in vitro}

Microscopic slides covered with a thin layer of polystyrene polymer (Leite and Nicholson, 1992) were used to observe the oval conidia morphogenesis. This methodology consisted of immersing the slides in a solution containing the polymer $190 \mathrm{~mm}$ diameter polystyrene Petri dish dissolved in $50 \mathrm{~mL}$ amyl acetate). After drying, the slides received $40 \mu \mathrm{L}$ of a conidial suspension $\left(10^{6}\right.$ oval conidia $\left.\mathrm{mL}^{-1}\right)$. The slides were placed in Petri dishes at $22 \pm 3{ }^{\circ} \mathrm{C}$ and maintained under constant fluorescent light $\left(50 \mu \mathrm{E} \mathrm{m}^{-2} \mathrm{~s}^{-1}\right)$ for $2,4,8,10,12,16$ or $24 \mathrm{~h}$. The slides were removed from Petri dishes after the end of each of the seven incubation times, and were covered with coverslips. The developmental stages of the oval conidia were observed and photographed under a light microscope.

\section{Conidial germination and infection process on sor- ghum leaves}

Sorghum leaf segments $\left(1 \mathrm{~cm}^{2}\right)$ removed from threeweek-old sorghum plants were sprayed with oval or falcate conidia suspensions $\left(10^{6}\right.$ conidia $\left.\mathrm{mL}^{-1}\right)$, both from the same strain. These segments were incubated in a moist chamber at $25{ }^{\circ} \mathrm{C}$ and removed at $0,4,8,12,24,32$ or 48 $\mathrm{h}$ to be fixed for $24 \mathrm{~h}$ at $4{ }^{\circ} \mathrm{C}$ in a modified Karnovsky fixer (2.5\% glutaraldehyde, $2.5 \%$ paraformaldehyde in 0.05 $\mathrm{M}$ cacodylate sodium buffer, $\mathrm{pH} 7.0$ plus $0.001 \mathrm{M} \mathrm{CaCl}_{2}$ ). Five leaf segments were used for each incubation time. The leaves were washed three times for $10 \mathrm{~min}$ in $0.05 \mathrm{M}$ sodium cacodylate buffer ( $\mathrm{pH} 7.2$ ) and fixed for one hour with $1 \%$ osmium tetroxide in the same buffer. Next, they were washed three times for $10 \mathrm{~min}$ in distilled water and dehydrated in a grade acetone series $(30,50,70,90 \%$ for one time and $100 \%$ for three times) for $10 \mathrm{~min}$ at each concentration. Finally, the leaves were dried to the critical point, coated with gold and examined under a scanning electron microscope (SEM). Each developmental stage of oval conidia was recorded by photography.

\section{Results}

Light microscopy analysis of oval conidia formation in vitro

Falcate conidia deposited on polystyrene covered slides germinated $2 \mathrm{~h}$ after incubation (hai) (data not shown). A central transverse septum was formed, and one germ tube protruded from the distal extremity from the central region of the germinated conidium. At 16 hai, the elongated germ tubes formed thick and highly vacuolated hyphae from which the oval conidia emerged from the lateral side and/or distal ends (Figure 1A).

\section{SEM analysis of oval conidia on sorghum leaves}

Results of the SEM analysis corroborated those of the light microscopy analysis and provided additional information on the initial infection events. The falcate conidia (Figure 1B) began germinating on the sorghum leaf surface at 4 hai (Figure 1C). Most falcate conidia developed a transversal septum and emitted a germ tube at one of the ends or in the central region, quickly forming septa (Figure 1C - 1D). The germ tube underwent differentiation at its free end forming an appressorium at 24 hai (Figure 1D). A dense mycelium developed on the leaf surface from germinated falcate conidia at 32 hai, and high density of oval conidia was observed (Figure 1E). Oval conidia were produced blastically from the tips of conidiogenic hyphae (Figure 2A). A scar is shown on an oval conidium edge, a vestige of the detaching region from a hypha (Figure 2B).

\section{Germination and infection of oval conidia}

Similar to the falcate, oval conidia increased in size after inoculation on the sorghum leaf surface and emitted a single germ tube from its end (Figure 2C) or center (Figure 2D) at 4 hai. Also, a single germ tube emerged and an appressorium arose at the tip after adherence and swelling of hyphae on the leaf surface (Figure 3A to D). Neither penetration of the germ tube nor appressorium through the stomata were observed. The penetration pore visibly surrounded by a thick ring was observed inside the appressorium that became detached from the leaf (Figure 3C - D). A mycelial mass containing acervuli with protruding setae developed from oval conidia at 48 hai (Figure 3E - F). Falcate conidia embedded in the mucilage were observed on these acervuli (Figure 3E - F).

\section{Discussion}

The infection process of sorghum leaves by the falcate type of conidia was well characterized (Wharton et al., 2001). In this study we demonstrated that oval conidia $C$. sublineolum can be produced from falcate conidia, 

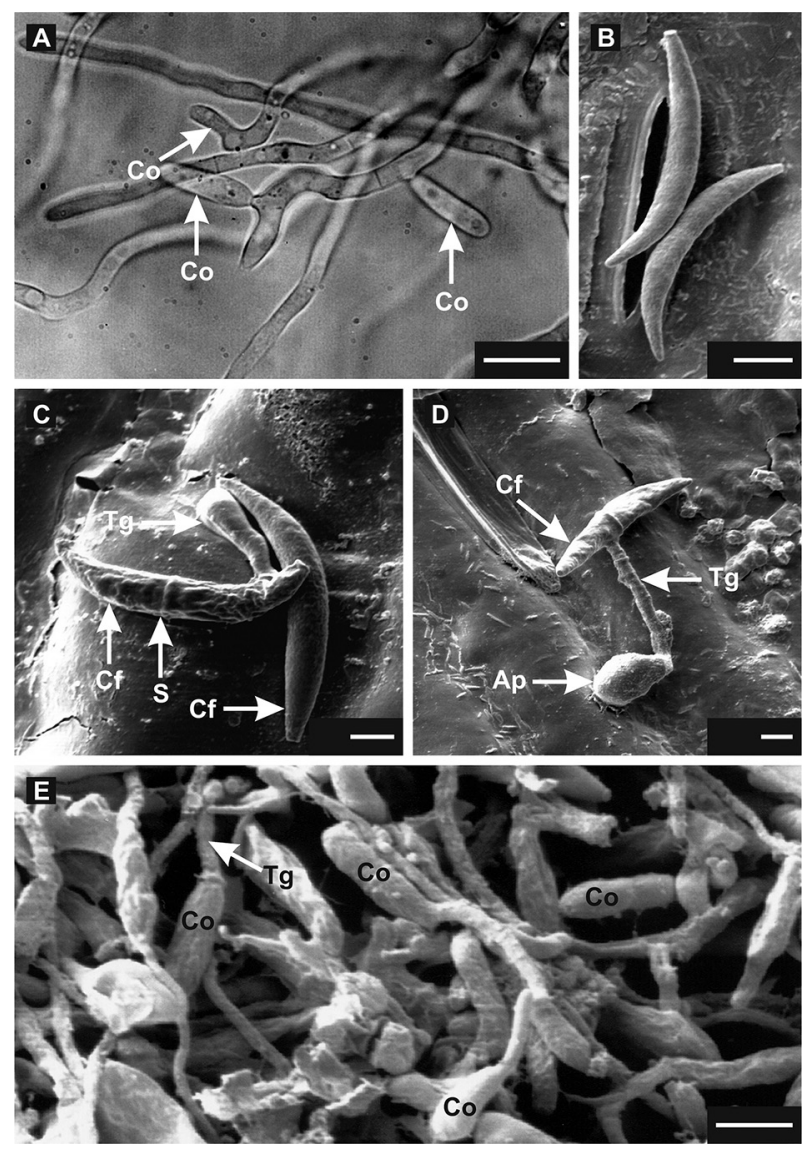

Figure 1 - Light (A) and Scanning electron micrographs (B to $E$ ) of Colletotrichum sublineolum conidia on polystyrene covered slides (A) and sorghum leaf surface (B to E). A: formation of oval conidia (Co) viewed laterally and at the tip of conidiogenic hypha developed from falcate conidia at $16 \mathrm{~h}$ after incubation. B: non-germinated falcate conidia of $C$. sublineolum over the stomata at $4 \mathrm{~h}$ after inoculation (hai). C: Falcate conidium (Cf) after 4 h-inoculation, showing the formation of the germ tube (Tg) and the septum (S). An ungerminated falcate conidium is visible. D: Formation of an appressorium (Ap) at the tip of a short germ tube from falcate conidia with septum 24 hai. E: Dense mycelium of $C$. sublineolum was formed from falcate conidia at 32 hai on sorghum leaves. From dense mycelium, oval conidia were produced and some of these initiated the process of germination. Scale bars: 4 (C), 4.5 (D), 6 (B, E) and 10 (A) $\mu \mathrm{m}$.

and that this new, or secondary, oval type of conidia is capable of infecting sorghum leaves. They were formed just following germination of the falcate conidia, and are known as microcyclic or precocious conidiation (Smith et al., 1981). This characteristic has been reported for several fungal species, including Colletotrichum spp. (Anderson and Smith, 1971; Nishihara, 1975; Slade et al., 1987; Panaccione et al., 1989; Hanlin, 1994; Leandro et al., 2001) and seems to vary with the strain used as well as with the growth medium, aeration, temperature, and other culture conditions (Lingappa and Lingappa, 1969;
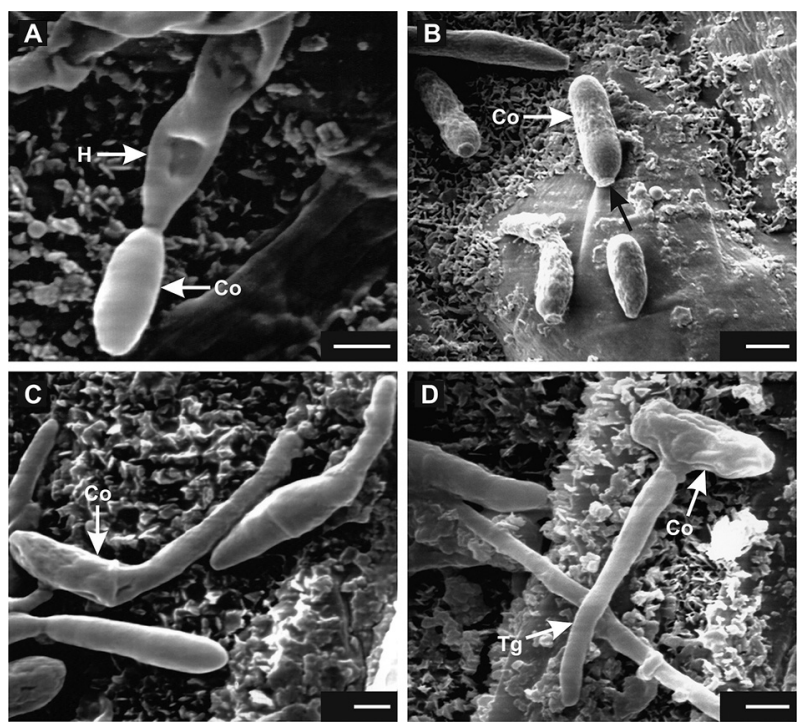

Figure 2 - Scanning electron micrographs showing the formation and germination of oval conidia (Co) of Colletotrichum sublineolum on the sorghum's leaf surface inoculated with oval (C - D) or falcate conidia (A - B). A: Mycelia of $C$. sublionelum formed from falcate conidia showing the formation of oval conidia at the tip of a conidiogenous hyphae $(\mathrm{H})$ at $24 \mathrm{~h}$ after inoculation (hai). B: Oval conidium and the point of separation (scar) of this from conidiogenous hyphae. C: Oval conidia germinated at 4 hai. D: Oval conidium collapsed after of emerging a long germ tube (Tg) at 4 hai. Scale bars: $3(A, C)$ and $3.5(B, D) \mu \mathrm{m}$.

Smith et al., 1981; Slade et al., 1987; Souza-Paccola et al., 2003; Zanette et al., 2009). For the Citrus pathogen, Colletotrichum acutatum, secondary conidia are formed just after the germination of the appressorium (Zulfiqar et al., 1996).

Nishihara (1975) reported that the oval conidia of C. graminicola were more aggressive than the falcate conidia. As the falcate conidia were not found in anthracnose lesions, Nishihara (1975) suggested that they could be produced only in vitro. Both falcate and oval conidia induce similar symptoms on maize plants (Panaccione et al., 1989). In addition, both types of conidia were found in diseased leaves regardless of the type of conidia used to inoculate the plants (Panaccione et al., 1989).

The role of oval conidia in the anthracnose disease cycle remains unknown. They were described in maize foliar lesions, xylem tissue, root epidermal cells and root hairs (Panaccione et al., 1989; Venard and Vaillancourt, 2007; Sukno et al., 2008). Sukno et al. (2008) speculated that the oval conidia may represent resting structures, which enable the fungus to remain inside the plant tissues in a metabolically inactive state, thereby preventing its recognition by the host. Our results clearly demonstrated the formation of oval conidia of $C$. sublineolum on the foliar superficies, before the penetration of the fungus in the host tissue, which suggests that oval conidia may also contribute to infections. 

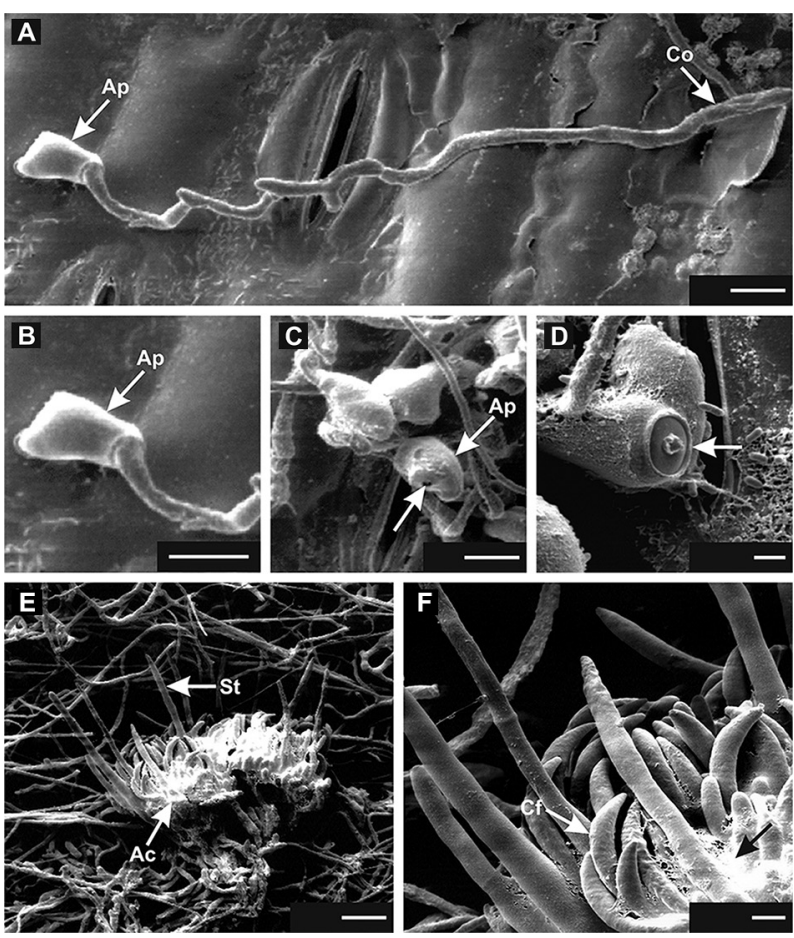

Figure 3 - Scanning electron micrographs showing the formation of an appressorium (Ap; A, B, C and D) and acervuli (Ac; E and F) of Colletotrichum sublineolum on the sorghum leaf surface inoculated with oval conidia (Co). A-B: Appressorium formation 24 (hai) of C. sublioneloum. C-D: Penetration pore (arrow) in appressorium detached from the leaf. E: Mycelium formed from germination of oval conidia showing an acervulus. Setae (St) can be seen protruding through the matrix of an acervulus. F: On an acervulus formed from oval conidia of $C$. sublineolum were reported falcate conidia (arrow) embedded in the mucilage. Scale bars: 3.5 (F) 9 (A, B, C, E); 12 (D) $\mu \mathrm{m}$.

Although the infection process by falcate conidia of $C$. sublineolum in sorghum has been well characterized (Wharton and Julian, 1996; Wharton et al., 2001; Basavaraju et al., 2009), little was known about the infection process by oval conidia. Germination of the oval conidia of $C$. sublineolum was completed within 4 hai, which is the range reported for other species within the genus (4-48 hai) (Bailey et al., 1992). Falcate conidia germinate within 9 hai, and a dark brown colored appressorium is formed after $18 \mathrm{~h}$ of spore germination (Wharton and Julian, 1996).

Both the oval and the falcate conidia of $C$. sublineolum had similar patterns of pre-penetration and penetration on sorghum leaves, which are characterized by globose and melanized appressoria adhered to the leaf surface and by the presence of the penetration pore at 24 hai. These events are critical for successful infection and further disease development (Mendgen and Deising, 1993; Mercure et al., 1994). A fast adhesion of the conidia on the maize leaves increases the success of infection (Mercure et al., 1994). The penetration pore is surrounded by an appressorial cone for some species of Colletotrichum (Xuei et al., 1988; Mould et al., 1991). In our study, appressorial cones were not observed, which is in agreement with previous reports (Politis and Wheeler, 1973; Politis, 1976; Mims, 1991; Latunde-Dada et al., 1996; Wharton et al., 2001).

In summary, we provided novel insights into the morphogenesis of secondary conidia of $C$. sublineolum, the oval type, which showed to be as effective as the falcate conidia to infect sorghum. High amounts of inoculum of the oval conidia can be obtained in a liquid media and the whole process is less cumbersome and more efficient than that used to produce inoculum of the falcate conidia (Souza-Paccola et al., 2003).

\section{Acknowledgments}

We thank Prof. Dr. Elliot Watanabe Kitajima from the Research Supporting Center in Electron Microscopy Applied to Agriculture Researches (NAP-MEPA/ESALQUSP/Piracicaba, SP-Brazil) for the electron microscope support; Dr. Carlos Roberto Casela from Embrapa Maize \& Sorghum/Sete Lagoas, MG - Brazil for kindly providing the sorghum seeds and $C$. sublineolum strains. This study was partially supported by the Coordination for the Improvement of Higher Level Personnel (CAPES).

\section{References}

Anderson, J.G.; Smith, J.E. 1971. The production of conidiophores and conidia by newly germinated conidia of Aspergillus niger (microcycle conidiation). Journal of General Microbiology 69: 185-197.

Basavaraju, P.; Shetty, N.P.; Shetty, H.S.; de Neergaard, E.; Jorgensen, H.J.L. 2009. Infection biology and defence responses in sorghum against Colletotrichum sublineolum. Journal of Applied Microbiology 107: 404-415.

Bailey, J.A.; O`Connel, R.J.; Pring, R.J.; Nasch, C. 1992. Infection strategies of Colletotrichum species. p. 88-120. In: Bailey, J.A.; Jeger, M.J., eds. Colletotrichum: biology, pathology and control. CABI, Wallingford, UK.

Casela, C.R.; Santos, F.G.; Ferreira, A.S. 2001. Reaction of sorghum genotypes to the anthracnose fungus Colletotrichum graminicola. Fitopatologia Brasileira 26: 197-200.

Hanlin, R.T. 1994. Microcycle conidiation: a review. Mycoscience 35: $113-123$.

Latunde-Dada, A.O.; O'Connell, R.J.; Nash, C.; Pring, R.J.; Lucas, J.A.; Bailey, J.A. 1996. Infection process and identity of the hemibiotrophic anthracnose fungus (Colletotrichum destructivum) from cowpea (Vigna unguiculata). Mycological Research 100: 1133-1141.

Leandro, L.F.S.; Gleason, M.L.; Nutter, F.W.Jr.; Wegulo, S.N.; Dixon, P.M. 2001. Germination and sporulation of Colletotrichum acutatum on symptomless strawberry leaves. Phytopathology 91: 659-664.

Leite, B.; Nicholson, R.L. 1992. Mycosporine-alanine: a selfinhibitor of germination from the conidial mucilage of Colletotrichum graminicola. Experimental Mycology 16: 76-86. 
Lingappa, B.T.; Lingappa, Y. 1969. Role of auto-inhibitors on mycelial growth and dimorphism of Glomerella cingulata. Journal of General Microbiology 56: 35-45.

Mendgen, K.; Deising, H. 1993. Infection structures of fungal plant pathogens: a cytological and physiological evaluation. New Phytologist 124: 193-213.

Mercure, E.W.; Kunoh, H.; Nicholson, R.L. 1994. Adhesion of Colletotrichum graminicola conidia to corn leaves: a requirement for disease development. Physiological and Molecular Plant Pathology 45: 407-720.

Mims, C.W. 1991. Using electron microscopy to study plant pathogenic fungi. Mycologia 83: 1-19.

Mould, M.J.R.; Boland, G.J.; Robb, J. 1991. Ultrastructure of the Colletotrichum trifolii - Medicago sativa pathosystem: pre-penetration events. Physiological and Molecular Plant Pathology 38: 179-194.

Nishihara, N. 1975. Two types of conidia of Colletotrichum graminicola (Ces.) G. W. Wils. formed on artificial media and their pathogenicity. Annals of the Phytopathological Society of Japan 41: 171-175.

Panaccione, D.G.; Vaillancourt, L.J.; Hanau, R.M. 1989. Conidial dimorphism in Colletotrichum graminicola. Mycologia 81: 875882.

Perumal, R.; Menz, M.A.; Mehta, P.J.; Katilé, S.; Gutierrez-Rojas, L.A.; Klein, R.R.; Klein, P.E.; Prom, L.K.; Schlueter, J.A.; Rooney, W.L.; Magill, C.W. 2009. Molecular mapping of Cg1, a gene for resistance to anthracnose (Colletotrichum sublineolum) in sorghum. Euphytica 165: 597-606.

Politis, D.J. 1976. Ultrastructure of penetration by Colletotrichum graminicola of highly resistant oat leaves. Physiology and Plant Pathology 8: 117-122.

Politis, D.J.; Wheeler, H. 1973. Ultrastructural study of penetration of maize leaves by Colletotrichum graminicola. Physiology and Plant Pathology 3: 465-471.

Powell, P.; Ellis, M.; Alameda, M.; Sotomayor, A. 1977. Effect of natural anthracnose epiphytotics on yield, grain quality, seed health, and seed borne fungi in Sorghum bicolor. Sorghum Newsletter 20: 77-78.

Slade, S.J.; Harris, R.F.; Smith, C.S.; Andrews, J.H. 1987. Microcycle conidiation and spore-carrying capacity of Colletotrichum gloeosporoides on solid media. Applied and Environmental Microbiology 53: 2106-2110.
Smith, J.E.; Anderson, J.G.; Deans, S.G.; Berry, D.R. 1981. Biochemistry of microcycle conidiation. p. 329-356. In: Cole, G.T.; Kendrick, B., eds. Biology of conidial fungi. Academic Press, New York, NY, USA.

Souza-Paccola, E.A.; Favaro, L.C.L.; Bomfeti, C.A.; Mesquita, S.F.P.; Paccola-Meirelles, L.D. 2003. Cultural characterization and conidial dimorphism in Colletotrichum sublineolum. Journal of Phytopathology 151: 383-388.

Sukno, S.A.; Garcia, V.M.; Shaw, B.D.; Thon, M.R. 2008. Root infection and systemic colonization of maize by Colletotrichum graminicola. Applied and Environmental Microbiology 74: 823832.

Sutton, B.C. 1980. The Coelomycetes. Fungi Imperfecti with Pycnidia Acervuli and Stromata. CABI, Wallingford, UK.

Venard, C.; Vaillancourt, L.J. 2007. Penetration and colonization of unwounded maize tissues by the maize anthracnose pathogen Colletotrichum graminicola and the related nonpathogen $C$. sublineolum. Mycologia 99: 368-377.

Wang, M.L.; Dean, R.; Erpelding, J.; Pederson, G. 2006. Molecular genetic evaluation of sorghum germplasm differing in response to fungal diseases: rust (Puccinia purpurea) and anthracnose (Collectotrichum graminicola). Euphytica 148: 319-330.

Warren, H.L. 1986. Leaf anthracnose. p. 10-11. In: Frederiksen, R.A., ed. Compendium of sorghum diseases. American Phytopathological Society, St. Paul, MN, USA.

Wharton, P.S.; Julian, A.M. 1996. A cytological study of compatible and incompatible interactions between Sorghum bicolor and Colletotrichum sublineolum. New Phytologist 134: 25-34.

Wharton, P.S.; Julian, A.M.; O`Connell, R.J. 2001. Ultrastructure of the infection of Sorghum bicolor by Colletotrichum sublineolum. Phytopathology 91: 149-158.

Xuei, X.L.; Jarlfors, U.; Kuc, J. 1988. Ultrastructural changes associated with induced systemic resistance of cucumber to disease: host response and development of Colletotrichum lagenarium. Canadian Journal of Botany 66: 1028-1038.

Zanette, G.F.; Nóbrega, G.M.A.; Paccola-Meirelles, L.D. 2009. Morphogenetic characterization of Colletotrichum sublineolum strains, causal agent of anthracnose of sorghum. Tropical Plant Pathology 34: 146-151.

Zulfiqar, M.; Brlansky, R.H.; Timmer, L.W. 1996. Infection of flower and vegetative tissues of citrus by Colletotrichum acutatum and C. gloeosporioides. Mycologia 88: 21-128. 